\title{
Cholangiolocellular carcinoma containing hepatocellular carcinoma and cholangiocellular carcinoma, extremely rare tumor of the liver : a case report
}

\author{
Mami Kanamoto", Tomoharu Yoshizumi"1, Toru Ikegami"), Satoru Imura1", \\ Yuji Morine", Tetsuya Ikemoto"), Nobuya Sano", and Mitsuo Shimada") \\ ${ }^{11}$ Department of Digestive and Pediatric Surgery, and ${ }^{2)}$ Department of Pathology, Institute of Health \\ Biosciences The University of Tokushima Graduate School, Tokushima, Japan
}

\begin{abstract}
Cholangiolocellular carcinoma (CLC) is an extremely rare malignant liver tumor which was first defined by Steiner, et al. in 1957 (1). CLC is thought to be derived from Hering's canal because tumor glands of CLC are morphologically similar to cholangioles. Recently, Theise, et al . reported that Hering's canal might be composed of hepatic stem cells (3). In addition, CLC sometimes contains a hepatocellular carcinoma (HCC) or cholangiocellular carcinoma (CCC) component within the tumor. Those findings suggest that CLC might originate from hepatic stem cells. On the other hand, because of its low frequency, clinicopatholigical features of CLC have not been fully clarified yet. We herein report a case of a 71-year old man with CLC. Based on preoperative imagings, the hepatic tumor was diagnosed as HCC, and he underwent a partial hepatectomy. The tumor contained both a HCC and CCC-like area. In immunohistochemistry, cytokeratin (CK) 7, CK20, CAM5.2 was positive, and CK19 was negative, therefore the tumor was diagnosed as CLC. The diagnostic criteria have not been described clearly, so CLC is difficult to diagnose preoperatively. Further studies are needed to clarify the clinical and clinicopatholigical features of CLC. J. Med. Invest. 55 : 161-165, February, 2008
\end{abstract}

Keywords : a rare tumor of the liver, cholangiocellular carcinoma, cholangiolocellular carcinoma, hepatic stem cell, hepatocellular carcinoma

\section{INTRODUCTION}

Cholangiolocellular carcinoma (CLC) is an extremely rare malignant liver tumor which was first defined by Steiner, et al . in 1957 (1). CLC is thought to be derived from Hering's canal because tumor glands of CLC are morphologically similar to cholangioles. Hering's canals are found in portal tracts of all sizes where they connect with the bile duct.
The small cells of Hering's canal have a basement membrane like the more distal portions of the biliary tree but an apical surface that appears similar to hepatic canalicular membrane. Recently, Theise, et al. reported that Hering's canal might be composed of hepatic stem cells (2). In addition, CLC sometimes contain a HCC or CCC component within a tumor. Those findings suggest that CLC might originate from hepatic stem cells. On the other hand, because

Received for publication October 22, 2007 ; accepted November $14,2007$.

Address correspondence and reprint requests to Mitsuo Shimada M.D., FACS, Department of Digestive and Pediatric Surgery, Institute of Health Biosciences, The University of Tokushima Graduate School, Kuramoto-cho, Tokushima 770-8503, Japan and Fax : +81-88-631-9698. 
of its low frequency, clinicopatholigical features of CLC have not been clarified as yet. Moreover, few cases have been reported in English literature. We herein present a case of CLC with its imagings and clinicopatholigical findings, and review the literature, especially focusing on hepatic stem cell origin.

\section{CASE REPORT}

A 71-year old man with chronic hepatitis $\mathrm{C}$ was referred for an evaluation of an asymptomatic liver mass that was detected by routine abdominal ultrasonography. Serum biochemistry and tumor markers, such as carcinoembryonic antigen (CEA), alpha fetoprotein (AFP), AFP-L 3\%, carbohydrate antigen (CA) 19-9, and protein induced by vitamin $\mathrm{K}$ absence-II (PIVKA-II) were within normal range (Table 1). The early phase of enhanced computed tomography (CT) showed marked enhancement of the tumor that measured approximately $1.0 \times 1.0 \mathrm{~cm}$ in the right lobe of the liver (Fig. 1). The tumor had homogeneous enhancement on delayed CT. The margin of the tumor was not clear. On T1- weighted magnetic resonance imagings (MRIs), the tumor was low intensity, whereas, on T2 with high intensity. On superparamagnetic iron oxide (SPIO) - enhanced liver MRIs, the tumor had marked enhancement with contrast material. On common hepatic angiography, the entire tumor showed hypervascularity, and pooling on the delayed images. Computed tomography angiography (CTA) showed the high density tumor. On computed tomography during arterial portography (CTAP) images, only the peripheral lesion of the tumor was enhanced.

Based on those preoperative imagings, the hepatic tumor was diagnosed to be HCC. The patient

Table 1. Laboratory findings

\begin{tabular}{llll}
\hline WBC & $5300 / \mathrm{ml}$ & BUN & $12 \mathrm{mg} / \mathrm{dl}$ \\
RBC & $396 \times 10^{4} / \mathrm{ml}$ & Cre & $0.81 \mathrm{mg} / \mathrm{dl}$ \\
HGB & $13.1 \mathrm{~g} / \mathrm{ml}$ & & \\
HCT & $39.5 \%$ & ICG-R 15 & $13 \%$ \\
PLT & $25.7 \times 10 / \mathrm{ml}$ & & \\
PT & $11.0 \mathrm{~s}$ & CEA & $1.4 \mathrm{ng} / \mathrm{L}$ \\
& & CA19-9 & $9 \mathrm{U} / \mathrm{ml}$ \\
GOT & $28 \mathrm{IU} / \mathrm{L}$ & PIVKA-II & $10 \mathrm{mAU} / \mathrm{ml}$ \\
GPT & $19 \mathrm{IU} / \mathrm{L}$ & AFP & $6 \mathrm{U} / \mathrm{ml}$ \\
ALP & $138 \mathrm{U} / \mathrm{L}$ & & \\
LDH & $157 \mathrm{U} / \mathrm{L}$ & Hbs Ag & $(-)$ \\
g-GTP & $67 \mathrm{U} / \mathrm{L}$ & Hbc Ab & $(-)$ \\
TP & $7.3 \mathrm{~g} / \mathrm{dl}$ & HCV Ab & $(+)$ \\
ALB & $3.9 \mathrm{~g} / \mathrm{dl}$ & HCV-RNA & $(-)$ \\
\hline
\end{tabular}

underwent a partial hepatectomy and liver cirrhosis was unclear. The tumor was felt in the right lobe of the liver, which was approximately $1.5 \mathrm{~cm}$, elastic hard, and moved well.

The resected tumor was measured $10 \times 15 \mathrm{~mm}$, whitish in color, solid, not encapsulated, and had an irregular margin (Fig. 2). Histological findings revealed that small ductules showing anastomos-
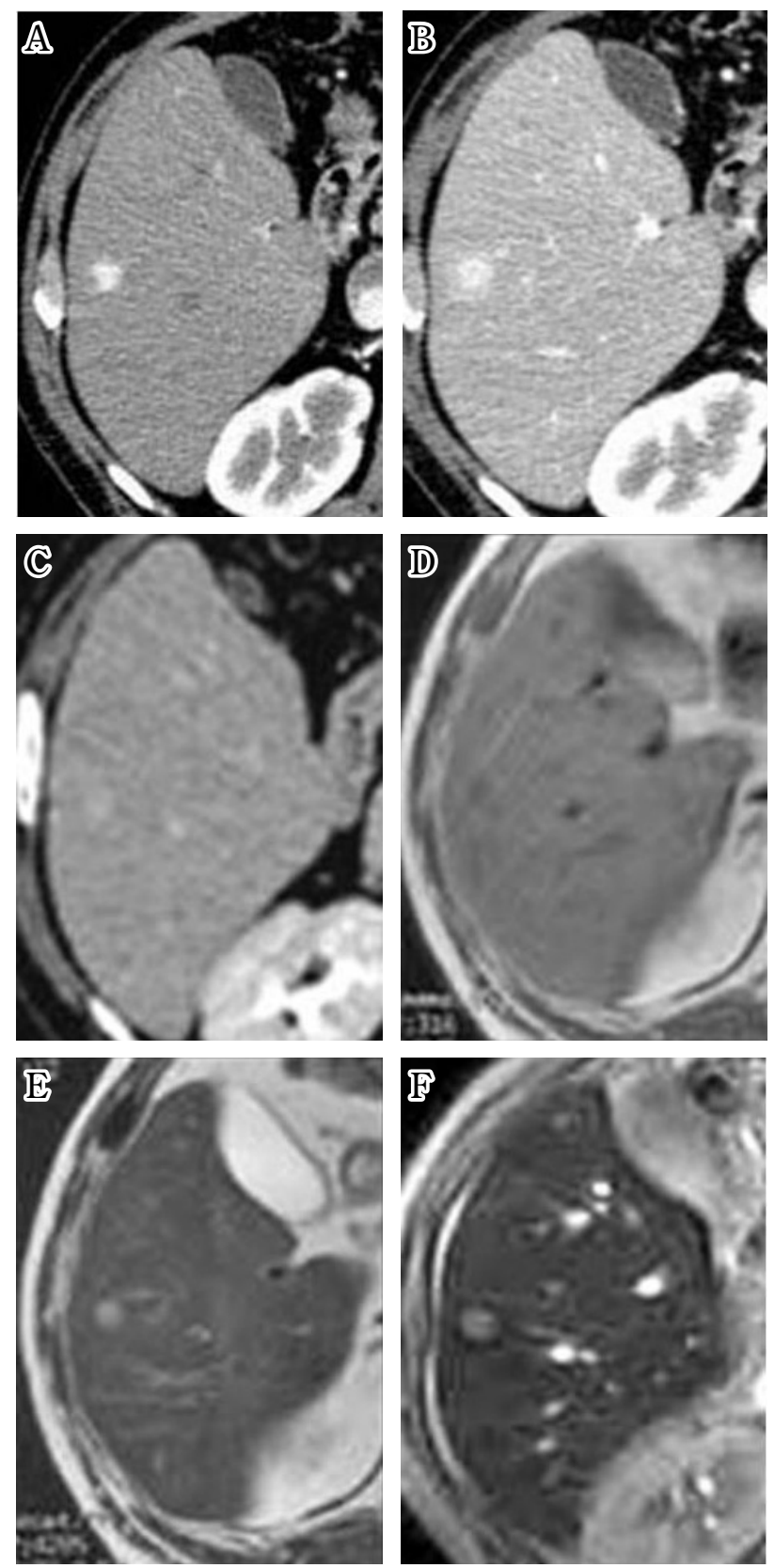

Fig. 1. (A) A hepatic arterial-phase computed tomography (CT) shows marked enhancement of the tumor that measured approximately $1.0 \times 1.0 \mathrm{~cm}$ in the right lobe of the liver. (B) A portal-phase scan. (C) A delayed-phase scan shows a homogeneous hyper attenuating tumor. (D) T1- weighted magnetic resonance imaging (MRI), the tumor is low intensity. (E) T2weighted MRI shows the tumor high intensity. (F) Superparamagnetic iron oxide (SPIO) - enhanced liver MRI show the tumor marked enhancement with contrast material. 
ing pattern, and composing of a moniliform structure. Tumor cells proliferated and replaced the surrounding normal tissue. In small areas of the tumor, relatively big ductules were detected and resembled cholangiocellular carcinoma. Furthermore, the tumor contained hepatocellular carcinoma (HCC)-
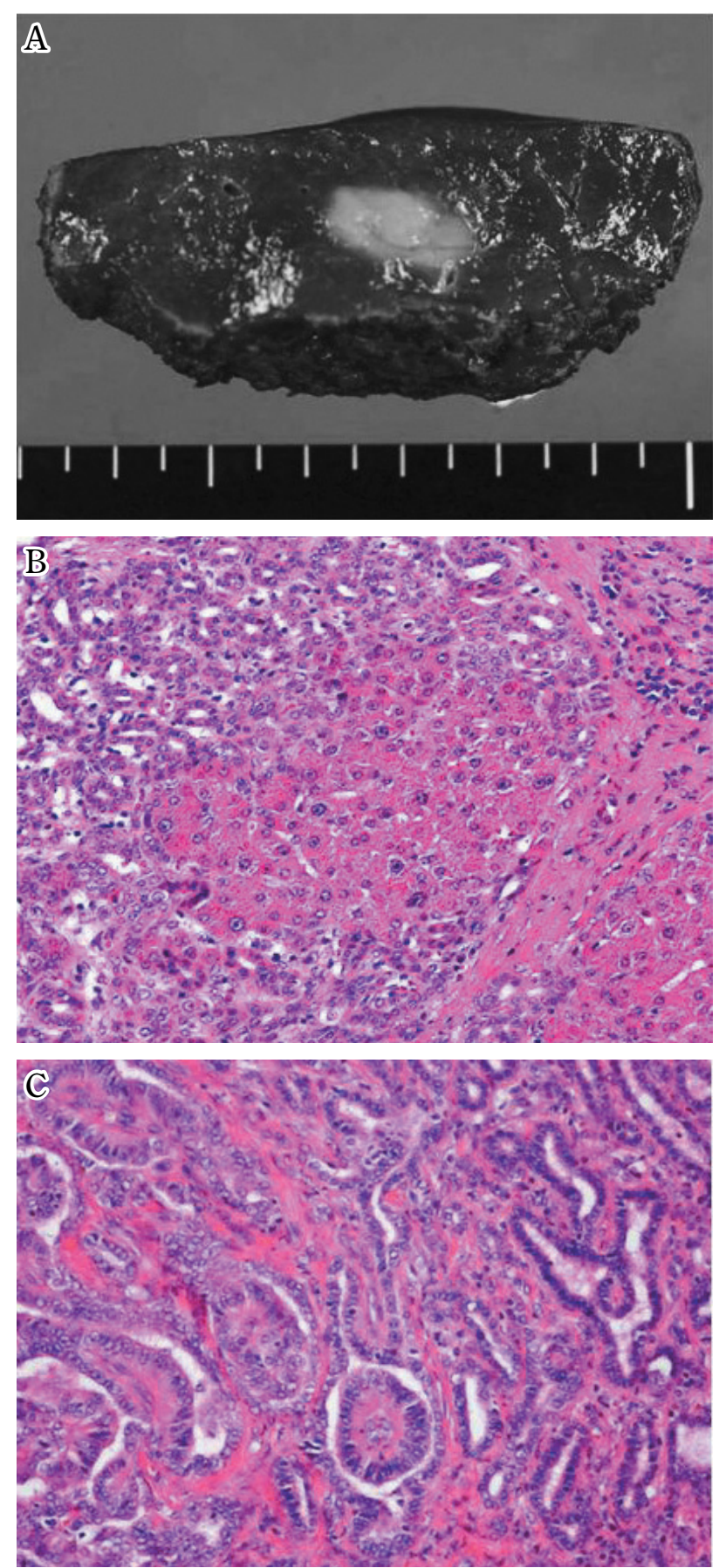

Fig. 2. (A) Macroscopic finding. The tumor is measured $10 \times 15 \mathrm{~mm}$ and whitish in color, solid, not encapsulated, and has irregular margin. (B, C) Microscopic findings. Small ductules show anastomosing pattern, and compose of moniliform structure. In focal area of the tumor, relatively big ductules are detected and resembled cholangiocellular carcinoma (B). Furthermore, the tumor contained an HCC-like area (C). (Hematoxylin and eosin stains. A: $\times 100, B: \times 200$ ). like area. In immunohistochemistry, cytokeratin (CK) 7, CK20, CAM5.2 was positive in a part of HCC, and CK19 was negative in CLCs (Fig. 3). Ckit was positive in part. The patient's postoperative recovery was uneventful and he has been doing well for 12 months after the operation.
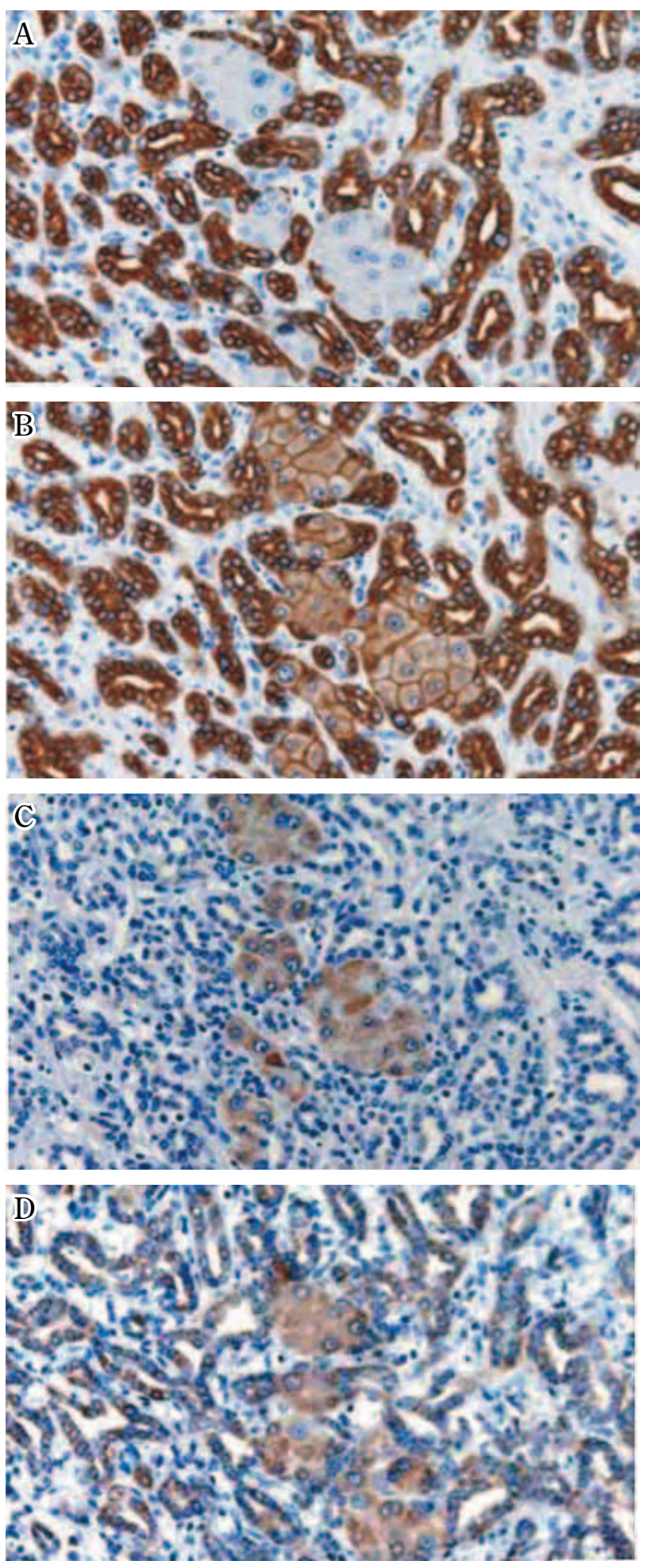

Fig. 3. Immunohistochemistry shows the tumor was positive for Cytokeratin (CK) 7 (A), CAM 5.2 (B), and negative for CK 19 (C). Tumor cells express c-kit (D). 


\section{DISCUSSION}

CLC is an extremely rare primary malignant tumor in the liver, and the frequency is as low as $0.56 \%$ in Japan (3). Because of its low frequency, clinicopatholigical features of CLC have not been clarified. The clinicopatholigical characteristics and findings of images were studied on 9 cases of CLC whose clinical courses were reported in Japan (3, 4). Five of these 9 patients (56\%) were infected with $\mathrm{HCV}$, one (11\%) was infected with $\mathrm{HBV}$, and 3 (33\%) were negative for both HCV antibody and HBs antigen (Table 2). This suggests that CLC has some association with chronic hepatitis, especially HCV antibody positive (3). Moreover, because many cases were infected with HCV or HBV, CLC had been often mistaken as HCC clinically. MRI was performed on 4 cases, and tumors showed high intensity on T1-weighted MRIs and low intensity on T2-weighted MRIs in all 4 cases. Angiography was performed on 7 cases. In 6 cases, the entire tumor showed hypervascularity. This finding suggests that hypervascularity is one of the characteristics of CLC.

In many cases, tumors were macroscopically whitish in color (5). Gross appearance of these tumors resembled CCC. Two cases contained CLC component only in histological findings. In the other 3 cases, tumors had HCC components, and another had CCC components. In the other 3 cases including our case, tumors had both components. Hepatic stem cells, which have the potential to differentiate into either hepatocytes or cholangio cells, have been thought to be cholangioles composing Hering's canals (6). Because CLC are thought to be derived from Hering's canal, CLC is suggested to have pluripotency to proliferate into $\mathrm{HCC}$ and/or CCC. In this case, the tumor has an HCC-like area or CCClike area. In addition, c-kit which is positive in immature cells was positive in this case $(7,8)$. This findings support the scenario that CLC is derived from hepatic stem cells. On the other hand, CK19, which is positive in normal cholangio cells, was negative in this tumor (9-12). These findings suggest that expressions of keratin in the tumor might have changed in the process of carcinogenesis. CK19 was positive in HCC-like area of the tumor, and CAM, which is usually expressed on HCC, was positive as well. These findings suggest that the tumor cells were derived from CLC which can differentiate into either HCC or CCC.

The prognosis of CLC was reported to be better than HCC. A case who survived for 6 years without recurrence was reported. However, the prognosis of CLC is not stated clearly yet, because of its lower frequency.

The diagnosis criteria on imaging have not been

Table 2. Clinicopatholigical features of CLC cases reported in Japan

\begin{tabular}{|c|c|c|c|c|c|c|c|}
\hline case & $\begin{array}{l}\text { age/ } \\
\text { sex }\end{array}$ & virus & $\begin{array}{l}\text { enhancement in } \\
\text { CT }\end{array}$ & MRI & angiography & $\begin{array}{l}\text { pathology/ } \\
\text { immunohistochemistry }\end{array}$ & prognosis \\
\hline \multirow[t]{2}{*}{ No. 1} & $69 / \mathrm{M}$ & $\mathrm{HCV}$ & mosaic & $\mathrm{T} 1:$ low & hyper- & HCC, CCC combined & 36 Months \\
\hline & & & & T2 : high & vascularity & CK $7(+)$ & alive \\
\hline \multirow[t]{2}{*}{ No. 2} & $67 / \mathrm{M}$ & $\mathrm{HBV}$ & periphery (+) & $\longrightarrow$ & hyper- & CLC & 33 Months \\
\hline & & & & & vascularity & CK 7, 19(+) & dead \\
\hline \multirow[t]{2}{*}{ No. 3} & $61 / \mathrm{M}$ & $(-)$ & mosaic & - & hyper- & HCC combined & 40 Months \\
\hline & & & & & vascularity & CEA, CA 19-9 (+) & alive \\
\hline \multirow[t]{2}{*}{ No. 4} & $68 / \mathrm{M}$ & $\mathrm{HCV}$ & mosaic & - & hyper- & HCC combined & 14 Months \\
\hline & & & & & vascularity & CEA $(+)$ & dead \\
\hline \multirow[t]{2}{*}{ No. 5} & $61 / \mathrm{M}$ & $\mathrm{HCV}$ & mosaic & 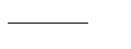 & hyper- & CLC & 72 Months \\
\hline & & & & & vascularity & CEA (+) & alive \\
\hline \multirow[t]{2}{*}{ No. 6} & $63 / \mathrm{F}$ & $\mathrm{HCV}$ & periphery $(+)$ & $\mathrm{T} 1$ : low & no findings & HCC reduplicated & 18 Months \\
\hline & & & & $\mathrm{T} 2:$ high & & & alive \\
\hline \multirow[t]{2}{*}{ No. 7} & $54 / \mathrm{F}$ & $(-)$ & periphery (+) & $\mathrm{T} 1:$ low & $\longrightarrow$ & CCC combined & 3 Months \\
\hline & & & & T2 : high & & CK $7(+)$, CA 19-9 (+) & alive \\
\hline \multirow[t]{2}{*}{ No. 8} & $58 / \mathrm{M}$ & $(-)$ & not enhanced & $\longrightarrow$ & $\longrightarrow$ & HCC, CCC combined & 1 Month \\
\hline & & & & & & CK $7(+)$ & dead \\
\hline \multirow[t]{2}{*}{ No. 9} & $71 / \mathrm{M}$ & $\mathrm{HCV}$ & mosaic & $\mathrm{T} 1:$ low & hyper- & HCC, CCC combined & 6 Months \\
\hline & & & & T2: high & vascularity & CK 7, $20(+)$ & alive \\
\hline
\end{tabular}

$\mathrm{HCV}$ : hepatitis $\mathrm{C}$ virus $\mathrm{HBV}$ : hepatitis B virus 
described clearly, so CLC is difficult to diagnose preoperatively. Further studies are needed to clarify the clinical and clinicopatholigical features of CLC.

\section{REFERENCES}

1. Steiner PE : Carcinoma of liver in United States. Acta Unio internat. Contra Cancrum 13 : 628645, 1957

2. Theise ND, Saxena R, Portmann BC, Thung SN, Yee H, Chiriboga L, Kumar A, Crawford $\mathrm{JM}$ : The canals of hering and hepatic stem cells in humans. Hepatology 30 : 1425-1433, 1999

3. Shiota K, Taguchi J, Nakashima O, Nakashima M, Kojiro M : Clinicopathologic study on Cholangiolocellular carcinoma, Oncology Reports $8: 263-268,2001$

4. Yamamoto M, Takasaki K, Nakano M, Saito A : Hepatic Recurrence of Cholangiocellular carcinoma : Report of a case, Hepato-Gastroenterology 43 : 1046-1050, 1996

5. Fukuoka Y, Hamanoue M, Fujiyoshi F, Sasaki M, Haruta $\mathrm{K}$, Inoue $\mathrm{H}$, Aiko $\mathrm{T}$, Nakajo $\mathrm{M}$ : Cholangiolocellular Carinoma of the Liver : CT and MR findings J Comput Assist Tomogr 24 : 809-812, 2000

6. Steiner PE, Higginson $\mathrm{J}$ : Cholangiolocellular carcinoma of the liver. Cancer $12: 753-759,1959$

7. Nomoto K, Tsuneyama K, Cheng C, Takahashi H, Hori R, Murai Y, Takano Y : Intrahepatic cholangiocarcinoma arising in cirrhotic liver frequently expressed p63-positive basal/stemcell phenotype, Pathol Res Pract 202 : 71-76, 2006

8. Stroescu C, Herlea V, Dragnea A, Popescu I :
The Diagnostic Value of Cytokeratins and Carcinoembryonic Antigen Immunostaining in Differentiating Hepatocellular Carcinomas from Intrahepatic Cholangiocarcinomas, J Gastrointest Liver Dis 15 : 9-14, 2006

9. Uenishi T, Kubo S, Hirohashi K, Yamamoto T, Ogawa M, Tanaka H, Shuto T, Kinoshita H : Expression of bile duct-type cytokeratin in noncancerous hepatocytes in patients with hepatitis B virus-related hepatocellular carcinoma, Hepatogastroenterology 50 : 1101-4, 2003

10. James J, Lygidalis NJ, van Eyken P, Tanka AK, Bosch KS, Ramaekers FC, DesmerV : Application of keratin immunocytochemistry and sirius red staining in evaluating intrahepatic changes with acute extrahepatic cholestasis due to hepatic duct carcinoma, Hepatogastroenterology $36: 151-5,1989$

11. Uenishi T, Hirohashi K, Shuto T, Tsukamoto T, Yamamoto T, Ogawa M, Kubo S, Tanaka H, Kinoshita $\mathrm{H}$ : Primary liver cancer with dual expression of hepatocyte and bile duct epithelial markers, Hepatogastroenterology 49 : 10924, 2002

12. Tanaka S, Hirohashi K, Uenishi T, Yamamoto T, Hamba H, Kubo S, Tanaka H, Shuto T, Ogawa M, Kinoshita $\mathrm{H}$ : A mixed hepatocellular carcinoma and cholangiocarcinoma : dual expression of biliary-type cytokeratin and hepatocyte specific marker, Hepatogastroenterology 51 : 839-41, 2004

13. Cha I, Cartwright D, Guis M, Miller TR, Ferrell $\mathrm{LD}$ : Angiomyolipoma of the liver in fine-needle aspiration biopsies : its distinction from hepatocellular carcinoma, Cancer 87 : 25-30, 1999 